\title{
KESALAHAN DESAIN RANGKAIAN DAN JAWABAN PADA IMPLEMENTASI COM3LAB VERSI 70013
}

\author{
Bunyamin, Abd. Djohar \\ Staf Pengajar Program Studi Teknik Elektro Fakultas Teknik Universitas Halu Oleo, Kendari \\ E-mail : bunyamin_arkol@yahoo.com
}

\begin{abstract}
Abstrak
Com3lab versi 70013 merupakan salah satu modul praktikum teknologi ACI di laboratorium Teknik Elektro Universitas Halu Oleo yang menggunakan animasi untuk memandu praktikan dalam mendesain rangkaian percobaan. Modul Com3lab menyediakan fasilitas report error yang akan muncul secara otomatis, bila terjadi kesalahan dalam pembuatan desain rangkaian atau jika menjawab salah pada sebuah pertanyaan yang diajukan. Tujuan penelitian adalah untuk mengetahui kesalahan yang sering terjadi dalam desain rangkaian pada modul Com3lab versi 70013 dan untuk mengetahui jumlah praktikan yang ideal untuk melaksanakan praktikum. Metode yang digunakan adalah simulasi dengan menggunakan modul Com3lab versi 70013. Hasil penelitian menunjukkan bahwa kesalahan desain rangkaian yang sering terjadi diakibatkan oleh salah satu kabel multimeter yang belum terhubung dan kabel yang dipasang terbalik. Jumlah praktikan yang ideal untuk melaksanakan praktikum menggunakan modul Com3lab versi 70013 adalah 2 orang.
\end{abstract}

Kata kunci: Com3lab, animasi, pertanyaan, laporan, kesalahan

\begin{abstract}
The fault on a circuit design and an answer on the implementation of the COM3LAB version 70013. The Com3lab version 70013 is one of the first experimental module ACI technologies in the laboratory of Electrical Engineering in the University of Halu Oleo, utilizing an animation which enables to guide the practitioners to design series of experiments. The module provides facilities of an error report appearing automatically, if there is an error in the design of a circuit, or if there is a wrong answer in a question. The purpose of study is to search any frequebtly mistakes in the circuit design utilizing the Com3lab module version 70013 and to determine the ideal number of the practitioner to carry out the practical work. In this study, the method utilised is to conduct a simulation using the Com3lab module version 70013. The results show that the frequent circuit design errors are caused by the unconnected multimeter wire and the reversing cable conncetion. The ideal number practicioners to carry out the experiment using the module are 2 people.
\end{abstract}

Keywords: Com3lab, animation, question, report, mistake

\section{Pendahuluan}

Laboratorium berbasis teknologi komputer mempunyai potensi besar menyelesaikan masalah kekurangan laboratorium konvensional pendukung proses belajar dan mengajar (Satwiko, 2008). Komputer memungkinkan para peneliti untuk menciptakan laboraturium virtual dalam komputer untuk melakukan eksperimen-eksperimen yang akan mahal sekali jika dilakukan di dalam sebuah laboratorium fisik (Nazief, 2006 \& Hayin, 2006).

Kemajuan teknologi industri melahirkan Man Machine Interface (MMI) yang merupakan kebutuhan standar di dunia industri manufaktur sebagai penghubung antara manusia dan mesin yang berfungsi melakukan pengendalian (control) dan pemantauan (monitoring and data acquisition) 


\section{DINAMIKA Jurnal Ilmiah Teknik Mesin}

pada proses industri (Aryani, 2011 \& Pamungkas, 2007).

MMI yang dibangun dari perangkat teknologi informasi dan komunikasi juga menjadi komponen utama pada perangkat laboratorium berbasis teknologi komputer yang dikembangkan saat ini untuk menyelesaikan masalah kekurangan laboratorium konvensional dan laboratorium di dunia maya (Zua, 2011).

Salah satu perangkat laboratorium berbasis teknologi komputer yang ada pada Jurusan Teknik Elektro Fakultas Teknik Universitas Halu Oleo yang dilengkapi dengan fasilitas MMI adalah Com3lab, yang merupakan bantuan Islamic Development Bank (IDB). Com3lab merupakan solusi yang ideal dalam praktikum di laboratorium, karena modul ini menggunakan animasi yang dapat memandu praktikan dalam mendesain rangkaian percobaan yang ada di dalamnya. Selain itu dalam media paktikum ini terdapat report error, merespon bila terjadi kesalahan dalam pembuatan desain rangkaian atau jika menjawab salah pada pertanyaan yang diajukan. Namun demikian sangat disayangkan karena pada dasarnya com3lab ini belum dilengkapi buku panduan untuk mempermudah pembelajaran mengenai cara pengoperasiannya

Oleh karena itu penelitian ini bertujuan untuk merangkum desain rangkaian yang benar pada modul com3lab versi 70013 (modul ACI), sehingga dapat membuat efisien waktu pelaksanaan praktikum dan menjadi dasar pada penyusunan panduan penggunaan com3lab versi 70013 .

\section{Metode Penelitian}

Metode yang digunakan dalam penelitian ini adalah ekperimen dan studi pustaka. Eksperimen dilakukan dengan simulasi atau peragaan praktikum modul com3lab dan kajian pustaka dilakukan untuk menjawab pertanyaan-pertanyaan yang diajukan oleh modul com3lab.

Prosedur tahapan pelaksanaan simulasi dimulai dengan menentukan banyaknya percobaan pada modul com3lab versi 70013, yaitu 14. Selanjutnya tahap start, yaitu mendesain rangkaian percobaan secara berurutan dari pertama hingga yang terakhir. Hal ini dilanjutkan denagn prosedur kerja pada setiap percobaan. Gambar berikut merupakan diagram alir penelitian.

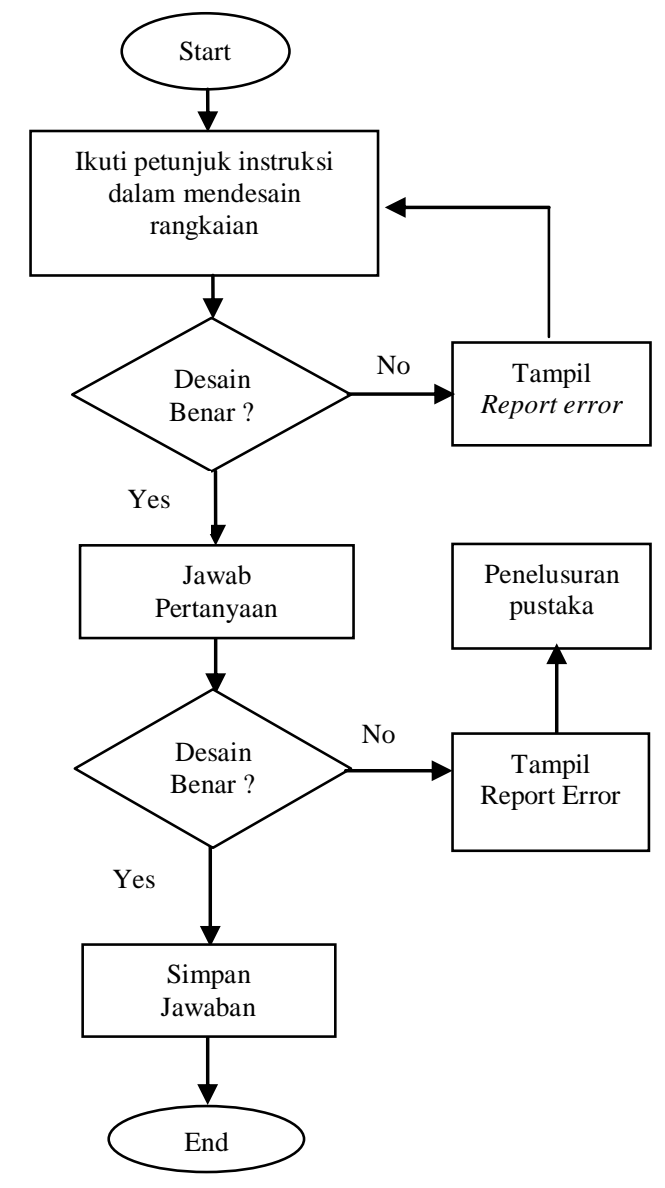

Gambar 1. Diagram alir penelitian

\section{Hasil dan pembahasan}

\section{Pengamatan Kesalahan Yang Sering Terjadi Pada Saat Eksperimen}

Pengambilan data pengamatan kesalahan yang sering terjadi pada saat ekperimen dilakukan dengan uji-coba pada praktikan yang belum mempelajari buku panduan, dan pada praktikan yang sudah mempelajari buku panduan. Sampai pada tahap ini kegiatan penelitian adalah pengambilan data pengamatan kesalahan praktikan dengan uji coba pada praktikan yang belum mempelajari buku panduan praktikum.

Kesalahan yang sering terjadi pada saat melakukan desain rangkaian pada umumnya akibat dari praktikan belum menghubungkan semua kabel multimeter, dan adanya kesalahan dalam menghubungkan kabel-kabel multimeter (hubungan terbalik). Selain hal tersebut kesalahan 


\section{DINAMIKA Jurnal Ilmiah Teknik Mesin}

dapat terjadi saat menjawab pertanyaan yang diajukan modul.

Gambar berikut ini menunjukan kesalahan yang sering terjadi pada saat eksperimen dilakukan bagi praktikan yang belum mempelajari buku penuntun.

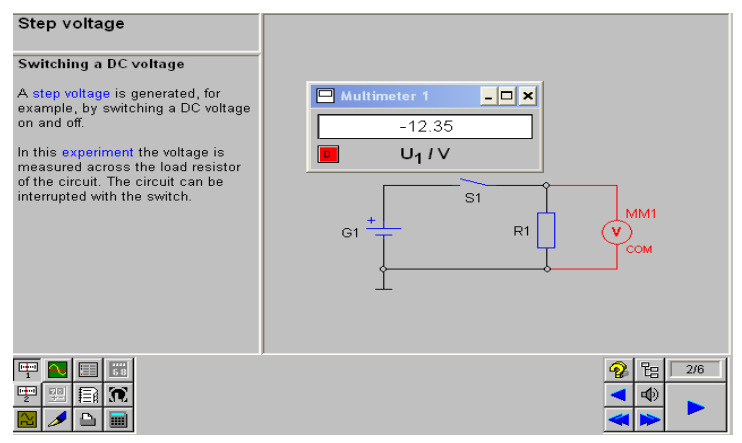

Gambar 2. Kesalahan pada saat eksperimen

Kesalahan yang terjadi akibat pemasangan kabel penghubung multimeter 1 terbalik

Gambar-gambar berikut menunjukan kesalahan yang terjadi akibat pemasangan kabel penghubung multimeter 1 terbalik

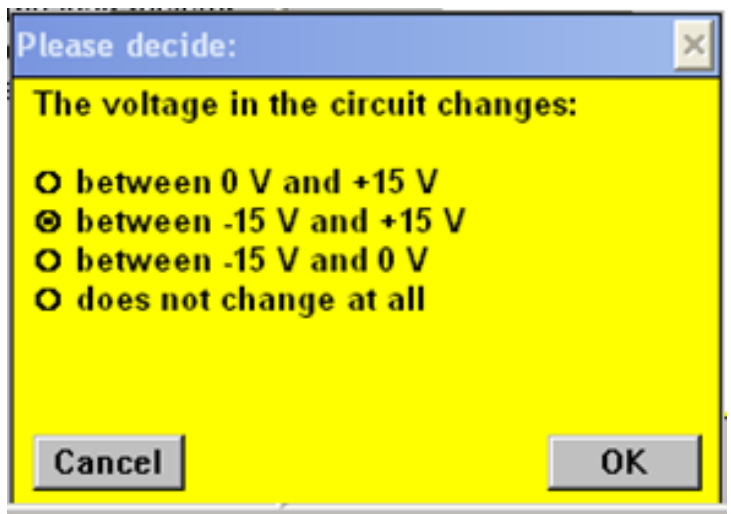

\section{Check your observation!}

Your answer is wrong.

Gambar 3. Kesalahan pada Step Voltage

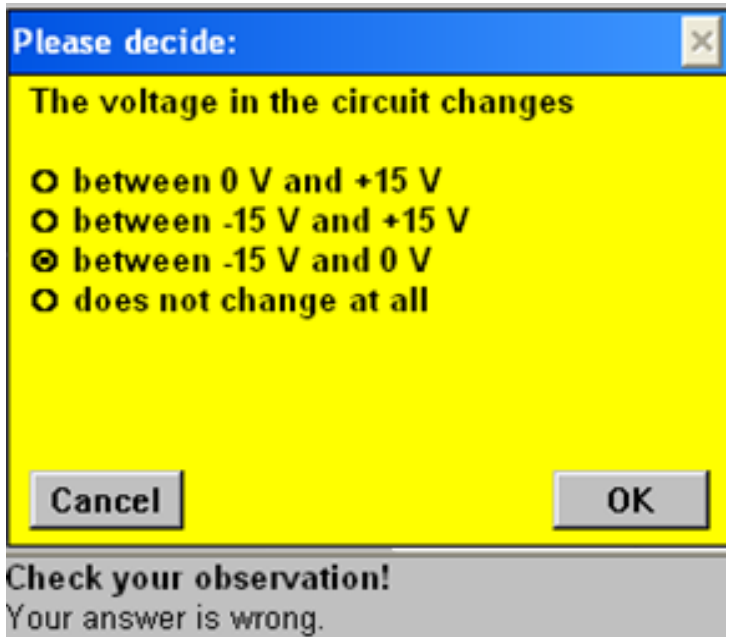

Gambar 4. Kesalahan pada Step Voltage(2)

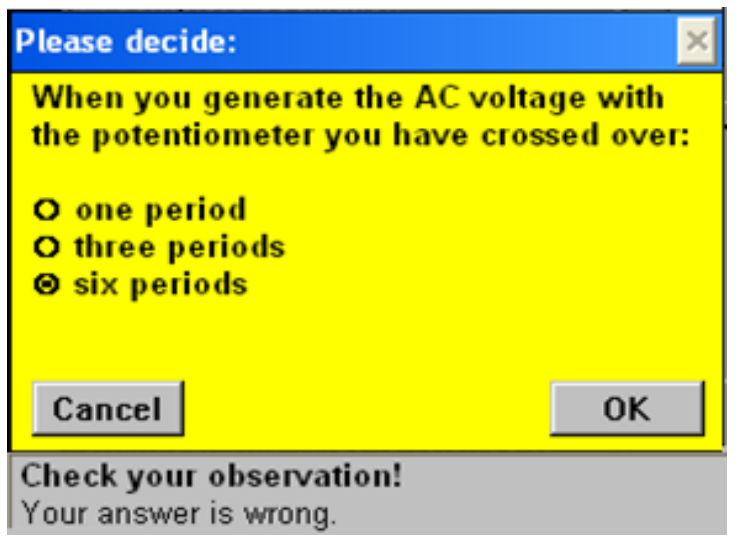

Gambar 5. Kesalahan padaContinues AC Voltage

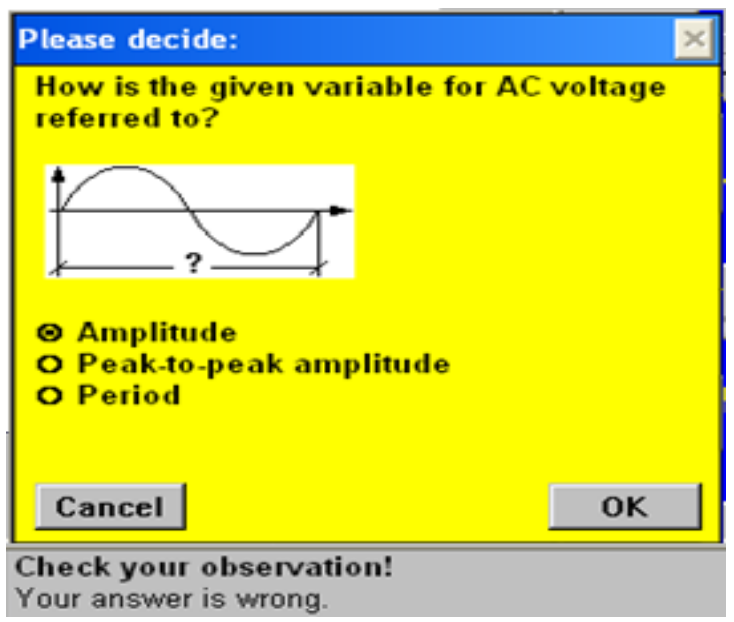

Gambar 6. Kesalahan pada Electrric generation $A C$ Voltage 


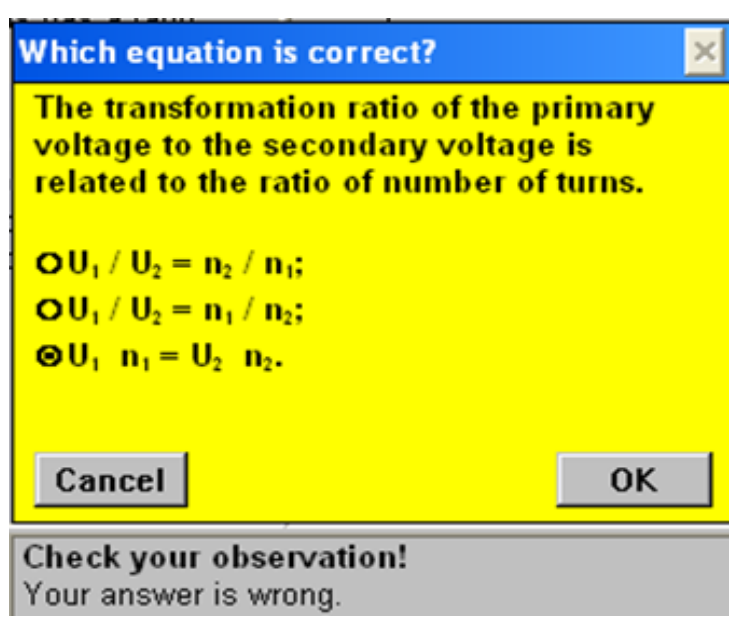

Gambar 7. Kesalahan pada Principle of the transformer

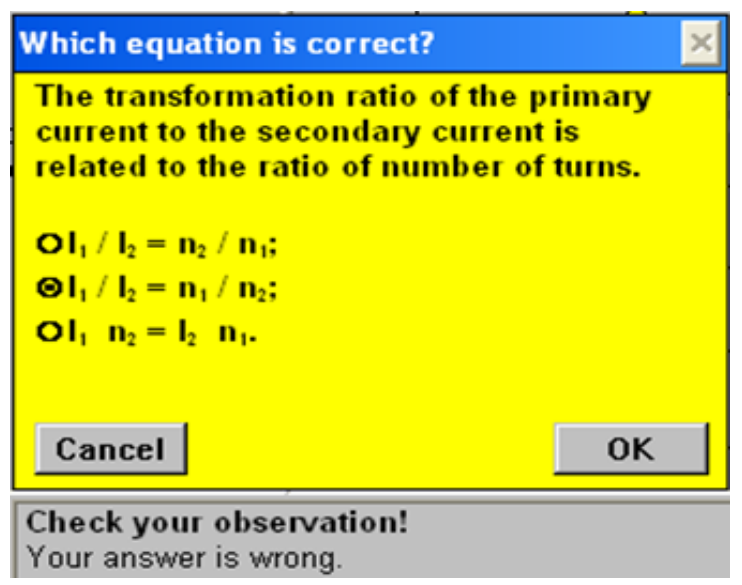

Gambar 8. Kesalahan pada Short-circuited transformer

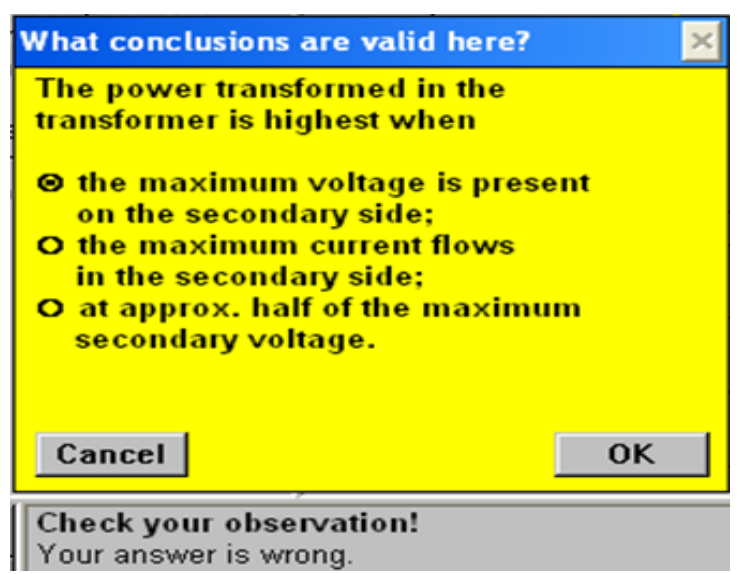

Gambar 9. Kesalahan pada Transformer under load

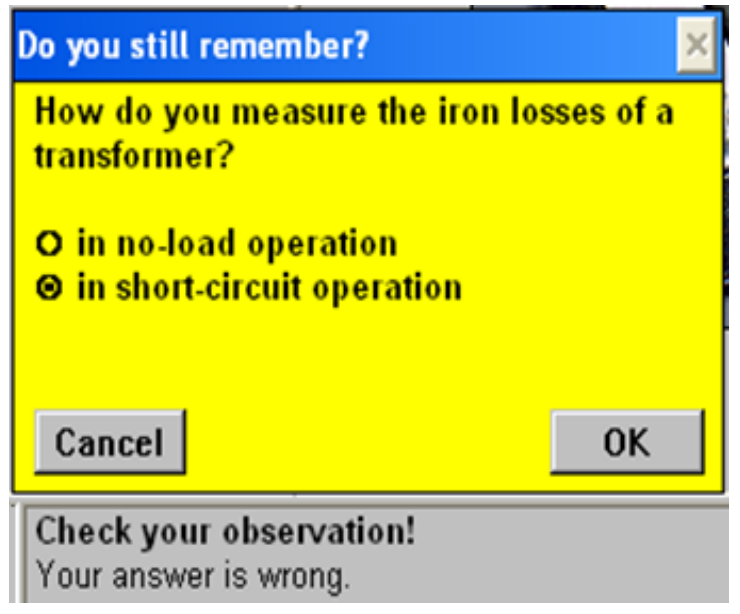

Gambar 10. Kesalahan pada Transformer looses

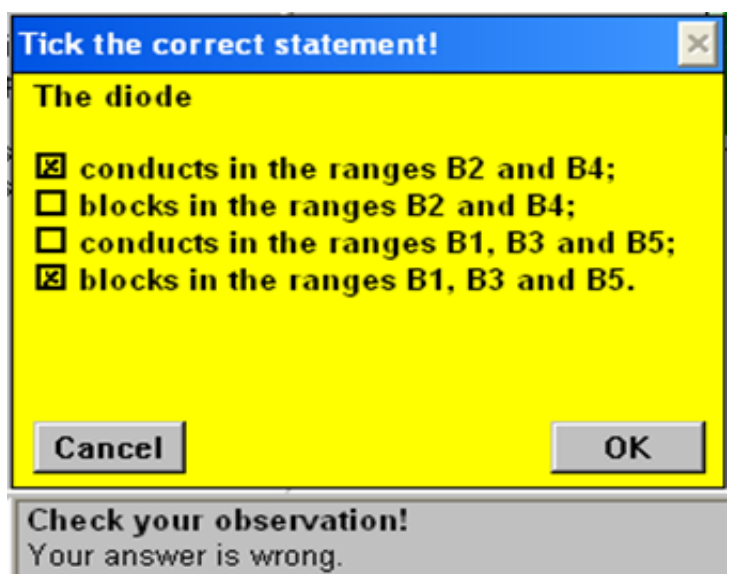

Gambar 11. Kesalahan pada The diode as current valve

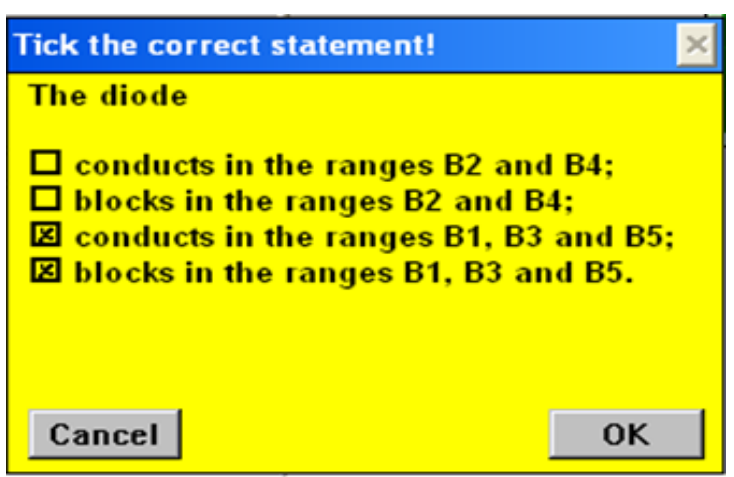

Check your observation!

Your answer is partly right and partly wrong.

Gambar 12. Kesalahan pada The diode as current valve(2) 


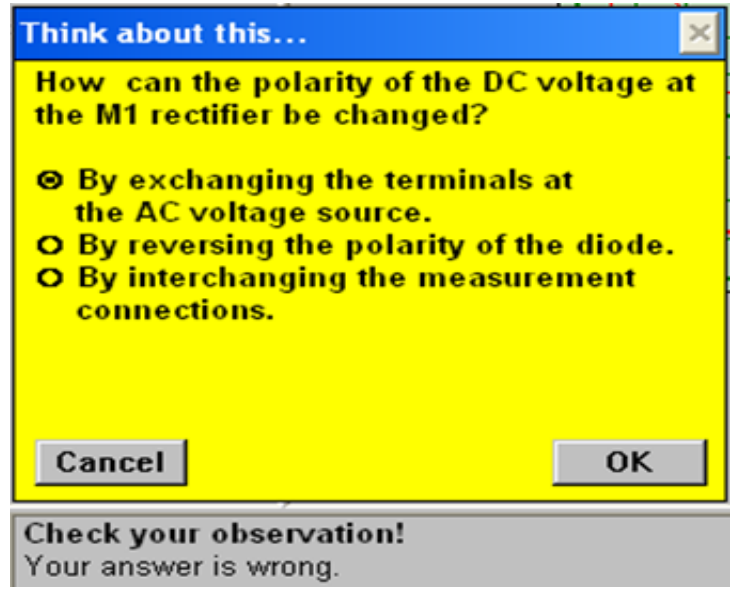

Gambar 13. Kesalahan pada M1 Rectifier

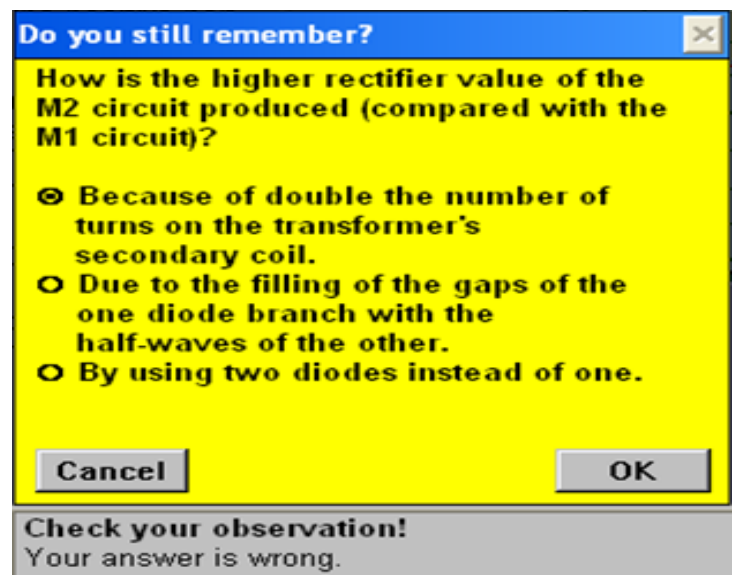

Gambar 14. Kesalahan pada M2 Rectifier

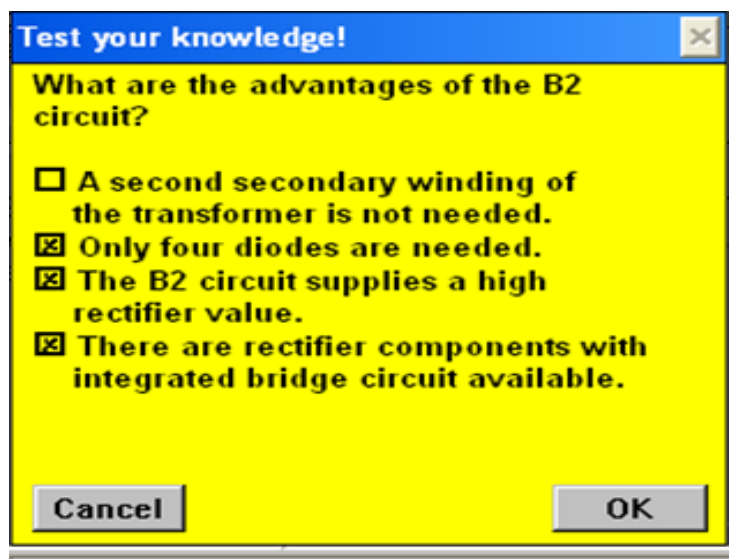

Note on how to proceed:

Don't just click on anything!

Gambar 15. Kesalahan pada M2 Rectifier(2)

\section{Rekapitulasi Data Kesalahan dan Durasi Waktu Praktikum}

Data kesalahan yang terjadi pada praktikum dengan jumlah anggota 3 orang sebelum mempelajari panduan dapat dilihat pada tabel berikut

Tabel 1. Kesalahan yang terjadi pada praktikum dengan jumlah anggota 3 orang sebelum mempelajari panduan

\begin{tabular}{|l|l|l|l|}
\hline No & \multicolumn{1}{|c|}{ Kelompok } & $\begin{array}{c}\text { Kesalahan } \\
\text { Rangkaian }\end{array}$ & $\begin{array}{c}\text { Kesalahan } \\
\text { Jawaban }\end{array}$ \\
\hline 1 & A & 5 & 4 \\
\hline 2 & B & 6 & 5 \\
\hline 3 & C & 5 & 5 \\
\hline 4 & D & 4 & 4 \\
\hline 5 & E & 4 & 3 \\
\hline
\end{tabular}

Data kesalahan yang terjadi pada praktikum dengan jumlah anggota 2 orang sebelum mempelajari panduan dapat dilihat pada tabel berikut

Tabel 2. Kesalahan yang terjadi pada praktikum dengan jumlah anggota 2 orang sebelum mempelajari panduan

\begin{tabular}{|l|l|l|l|}
\hline No & Kelompok & $\begin{array}{c}\text { Kesalahan } \\
\text { Rangkaian }\end{array}$ & $\begin{array}{c}\text { Kesalahan } \\
\text { Jawaban }\end{array}$ \\
\hline 1 & A & 5 & 5 \\
\hline 2 & B & 5 & 4 \\
\hline 3 & C & 4 & 5 \\
\hline 4 & D & 5 & 5 \\
\hline 5 & E & 6 & 4 \\
\hline 6 & F & 4 & 4 \\
\hline 7 & G & 5 & 5 \\
\hline
\end{tabular}

Data lama praktikum dan keaktifan praktikan bagi kelompok dengan jumlah anggota 3 orang setelah mempelajari panduan dapat dilihat dalam tabel berikut 


\section{DINAMIKA Jurnal Ilmiah Teknik Mesin}

Tabel 3. Data lama praktikum dan keaktifan praktikan bagi kelompok dengan jumlah anggota 3 orang setelah mempelajari panduan

\begin{tabular}{|l|l|l|l|l|}
\hline No & Kelompok & Kesalahan & $\begin{array}{c}\text { Lama } \\
\text { Praktikum } \\
\text { (Jam) }\end{array}$ & $\begin{array}{c}\text { Anggota } \\
\text { Aktif }\end{array}$ \\
\hline 1 & A & 1 & 4.10 & 2 \\
\hline 2 & B & 1 & 4.5 & 2 \\
\hline 3 & C & - & 4.10 & 3 \\
\hline 4 & D & 2 & 4.20 & 3 \\
\hline 5 & E & - & 4.15 & 2 \\
\hline
\end{tabular}

Data lama praktikum dan keaktifan praktikan bagi kelompok dengan jumlah anggota 2 orang setelah mempelajari panduan dapat dilihat dalam tabel berikut

Tabel 4. Data lama praktikum dan keaktifan praktikan bagi kelompok dengan jumlah anggota 3 orang setelah mempelajari panduan

\begin{tabular}{|l|l|l|l|l|}
\hline No & Kelompok & Kesalahan & $\begin{array}{c}\text { Lama } \\
\text { Praktikum } \\
(\text { Jam })\end{array}$ & $\begin{array}{c}\text { Anggota } \\
\text { Aktif }\end{array}$ \\
\hline 1 & A & 1 & 4.10 & 2 \\
\hline 2 & B & 2 & 4.5 & 2 \\
\hline 3 & C & - & 4.10 & 2 \\
\hline 4 & D & - & $4 . .10$ & 2 \\
\hline 5 & E & 1 & 4.5 & 2 \\
\hline 6 & F & 1 & 4.5 & 2 \\
\hline 7 & G & 1 & 4.10 & 2 \\
\hline
\end{tabular}

\section{Kesimpulan}

Kesimpulan dalam penelitian ini adalah dengan menggunakan demonstrasi modul com3lab versi 70013, untuk sejumlah praktikan yang belum mempelajari buku panduan, kesalahan banyak ditemukan dalam membuat desain rangkaian dan dalam menjawab pertanyaan yang diajukan. Selain itu, kesalahan desain rangkaian juga banyak ditemukan akibat salah satu kabel multimeter yang belum terhubung dan kabel multimeter yang dihubungkan terbalik.

Hasil demonstrasi juga menunjukan bahwa jumlah praktikan yang ideal untuk melaksanakan praktikum dengan menggunakan modul com3lab versi 70013 adalah 2 orang.

\section{Daftar Pustaka}

Arfayani. 2011, " Pembuatan modul praktikum rangkaian digital berbasis com3lab versi 70017”. Tugas Akhir Universitas Haluoleo.

Hayin N. 2006, "Pembuatan petunjuk modul praktikum Teknik Modulasi”. Tugas Akhir Politeknik elektronika negeri Surabaya.

Nazief B. 2006, "RI Grid : Usulan Pengembangan Infrakstruktur Komputasi Grid Nasional”, Prosiding e-Indonesia Initiative 2006.

Pamungkas B. 2007, “Pembuatan petunjuk modul praktikum lektronika digital 1 dengan menggunakan kit trainer berbasis CBL". Tugas Akhir Politeknik elektronika negeri Surabaya.

Satwiko P. 2008, "Panduan Teknologi Komputer dan Kesusasteraan Etnis untuk Alternatif Pendidikan Arsitektur Indonesia Baru”. Jurnal Ilmiah Universitas Atmajaya Jogjakarta.

Zua L. 2011, "Pembuatan modul praktikum rangkaian listrik berbasis com3lab versi 70011 ”. Tugas Akhir Universitas Haluoleo. 